ACCEPTED MANUSCRIPT

\title{
Effects of stacking sequences on static, dynamic mechanical and thermal properties of completely biodegradable green epoxy hybrid composites
}

To cite this article before publication: Senthilkumar Krishnasamy et al 2019 Mater. Res. Express in press https://doi.org/10.1088/2053$1591 / \mathrm{ab} 3 \mathrm{ec} 7$

\author{
Manuscript version: Accepted Manuscript \\ Accepted Manuscript is "the version of the article accepted for publication including all changes made as a result of the peer review process, \\ and which may also include the addition to the article by IOP Publishing of a header, an article ID, a cover sheet and/or an 'Accepted
} Manuscript' watermark, but excluding any other editing, typesetting or other changes made by IOP Publishing and/or its licensors"

This Accepted Manuscript is @ 2019 IOP Publishing Ltd.

During the embargo period (the 12 month period from the publication of the Version of Record of this article), the Accepted Manuscript is fully protected by copyright and cannot be reused or reposted elsewhere.

As the Version of Record of this article is going to be / has been published on a subscription basis, this Accepted Manuscript is available for reuse under a CC BY-NC-ND 3.0 licence after the 12 month embargo period.

After the embargo period, everyone is permitted to use copy and redistribute this article for non-commercial purposes only, provided that they adhere to all the terms of the licence https://creativecommons.org/licences/by-nc-nd/3.0

Although reasonable endeavours have been taken to obtain all necessary permissions from third parties to include their copyrighted content within this article, their full citation and copyright line may not be present in this Accepted Manuscript version. Before using any content from this article, please refer to the Version of Record on IOPscience once published for full citation and copyright details, as permissions will likely be required. All third party content is fully copyright protected, unless specifically stated otherwise in the figure caption in the Version of Record.

View the article online for updates and enhancements. 
*Corresponding author: Rajini N, E-mail: rajiniklu@gmail.com, Tel.: +919942139392; Fax: +914563289042, Suchart Siengchin, E-mail: suchart.s.pe@tggs-bangkok.org Tel. +66890609999, Senthil Muthu Kumar T, E-mail: tsmkumar@klu.ac.in, Tel.: +919442394350

\section{Senthilkumar $\mathbf{K}^{\mathrm{a}, \mathrm{d}}$, Senthil Muthu Kumar $\mathbf{T}^{\mathrm{a}, \mathbf{d}^{*}}$, Chandrasekar $\mathbf{M}^{\mathrm{b}}$, Jiratti Tengsuthiwat ${ }^{\mathrm{c}, \mathrm{d}}$,} ${\text { Rajini } \mathbf{N}^{\mathrm{a}} \text {, Suchart Siengchin }}^{\mathrm{d}^{*}}$, Sikiru O. Ismail ${ }^{\mathrm{e}}$, Brintha N $\mathbf{C}^{\mathrm{f}}$

a Department of Mechanical Engineering, Kalasalingam Academy of Research and Edúcation, Krishnankoil-626126, Tamil Nadu, India

${ }^{\mathrm{b}}$ Department of Aerospace Engineering, Faculty of Engineering, University Putra Malaysia, 43400 UPM Serdang, Selangor, Malaysia

${ }^{\mathrm{c}}$ Department of Mechanical Engineering Technology, College of Industrial Technology (CIT), King Mongkut's University of Technology North Bangkok, 1518 Wongsawang Road, Bangsue, Bangkok 10800, Thailand

${ }^{\mathrm{d}}$ Department of Mechanical and Process Engineering, The Sirindhorn International Thai-German Graduate School of Engineering (TGGS), King Mongkut's University of Technology North Bangkok, 1518 Wongsawang Road, Bangsue, Bangkok 10800, Thailand

${ }^{\mathrm{e}}$ Manufacturing, Materials, Biomedical and Civil Division, School of Engineering and Computer Science, University of Hertfordshire, Hatfield, Hertfordshire AL10 9AB, England, United

${ }^{\mathrm{f}}$ Department of Computer Science and Engineering, Kalasalingam Academy of Research and Education, Krishnankoil-626126, Tamil Nadu, India

\section{Abstract}

Hybrid composites reinforced with the hemp (H) and sisal (S) in various layering arrangements were fabricated, using hot press moulding technique and their properties were investigated. The flexural, impact and thermal properties of the sisal fibre reinforced composites improved significantly with the introduction of hemp in their stacking sequence. However, the hybrid composite configurations at which the optimum properties occur vary from one stacking sequence to the other. The hybrid composites with sisal in skin and hemp at core (SHHS) showed balanced mechanical properties, while the HHSS composites provided the best thermal resistance. The increased strength, stiffness and thermal stability for certain hybrid configurations indicate their suitability for structural engineering applications.

Keywords: Green epoxy, hybrid composites, dynamic mechanical properties, thermal properties, ANOVA.

\section{Introduction}


Natural fibre reinforced composites (NFCs) are witnessing huge demand and interest not only because of their low cost, high strength to weight ratio, biodegradability, low density, and plenty of availability, but also due to the urgency in addressing the environmental, sustainability and economic concerns [1-3]. Hence, there is a continuous increase in the research and development of new green materials based on plant fibres and bio-resins. Even though, NFCs are used in many applications, such as automotive components, aerospace parts, sporting goods and building materials in construction industry, they still have some restrictions in usage due to their hygroscopic nature, poor wettability and thermal stability, among others [4,5]. These shortcomings can be rectified effectively by hybridisation of the natural fibres with other synthetic or natural fibres $[6,7]$.

Studies have been reported on the hybridization of natural-synthetic and natural-natural fibres in synthetic and biopolymer matrices. Some researchers have investigated the mechanical properties of the hybridisation of sisal/glass fibre and sisal/silk fibres in unsaturated polyester resin [8,9]. They reported that the tensile properties of the hybridised unsaturated polyester composites with sisal and glass fibres improved substantially [8]. Furthermore, they also found significant improvement in the flexural and compressive strengths of the sisal/silk hybrid composites [9]. Similarly, a study on the jute/banana fibre reinforced epoxy hybrid composites showed an increased mechanical and thermal properties with the addition of banana fibre up to $50 \%$ [10]. In another study, the dynamic mechanical analysis of short bamboo/glass fibre polypropylene hybrid composites showed an increased storage modulus, indicating high stiffness of the hybrid composites when compared with the composites and the pure matrix [11]. Alkali treatment of palmyra palm leaf stalk and jute fibres in polyester based hybrid composites improved the storage and loss modulus of the hybrid composites. The hybrid with maximum jute concentration possessed maximum damping behaviour [12]. The effect of layering of different fibres on the epoxy based hybrid composites was analysed. Glass fibre was used as external layers of the hybrid composites, while banana and flax were layered in the inner core. The lamination of glass fibre increased the mechanical properties, thermal stability and flame resistance of the hybrid composites [13]. The hybridisation of glass fibres with hemp fibre polypropylene composites improved the impact and the thermal properties [14]. The effects of fibre loading on the thermal stability of jute/bagasse epoxidised phenolic novolac resin hybrid composites was studied. The increase in thermal stability was observed when there was an increase in the bagasse fibre loading [15]. Therefore, the above discussed relevant literature have established the benefits of hybridisation technique towards improvements of properties of composite materials.

According to Pickering et al. [16], the usage of natural fibre reinfroced composites in several applications could be increased by introducing a woven type of fiber composites owing to their (i) high strength and (ii) unique structure. Furthermore, woven fibre reinfroced composites can be used in the high strength structures due to their improved fracture toughness. Kohndker et al. [17] reported that the woven type of fiber could be used in car interiors and aircraft, where the intended applications were found to be suitable in the long-term usage. Rajesh and Jeyaraj [18] reported that introducing natural fibre in the form of woven fabric could improve the strength of the composite. Hence, in the present study, the natural fibres in the form of woven type have been chosen by the authors.

$82 \quad$ Nowadays, bio-polymers such as (i) polyhydroxybutyrate (ii) polylactic acid (iii) soya 83 oil-based epoxy (iv) modified cellulose (v) starch and (vi) lignin and their composites were also 
studied by many researchers for replacing the conventional thermoset or thermoplastic based polymers due to the increased environmental concerns involved in their disposal and recycling [19][20][21][22][23][24]. However, works on completely biodegradable polymer composite reinforced with hemp and sisal fibres were less common in the literature and hardly the effect of stacking sequence on their mechanical and thermal properties were addressed. In this present study, an attempt was made to develop hybrid composites with hemp and sisal fibre/as reinforcement and green epoxy as the polymer matrix. The effects of stacking sequence on the hybrid composites were analysed by varying the sisal and hemp fibre in different layering arrangements. Properties such as flexural, impact and dynamic mechanical properties were investigated besides their thermal stability. For the purpose of comparison, the properties of composites with pure hemp and pure sisal were also reported. The hybrid composites under investigation were developed to suit the needs of structural applications in the automotive, construction industries and interior decorations.

\section{7}

98

99

100

101

102

103

104

105

\section{Experimental procedure}

\subsection{Materials}

Bidirectional woven fibre mat of hemp (yarn diameter $=486.333 \pm 11.96 \mu \mathrm{m}$ ) and sisal fibres (yarn diameter $=504.496 \pm 3.07 \mu \mathrm{m})$ were supplied by Nirmala Industries, Hyderabad, India. The images of the fibre mats and their scanning electron microscopic (SEM) micrographs are presented in Fig. 1. Green epoxy (SR Greenpoxy $56^{\mathrm{B}}$ ), a produce with high content of carbon from plant origin and the hardener (SD Surf Clear ${ }^{\circledR}$ ) was supplied by Sicomin Epoxy Systems, France. The properties of both the fibre mats and the green epoxy resin are presented in Tables 1 and 2. 
Table 1 Properties and composition of hemp and sisal fibre mats [1,25].

\begin{tabular}{lcc}
\hline Properties & Hemp fibre & Sisal fibre \\
\hline Density $\left(\mathrm{g} / \mathrm{cm}^{3}\right)$ & 1.48 & 1.50 \\
Tensile Strength $(\mathrm{MPa})$ & 690 & $511-635$ \\
Young's Modulus $(\mathrm{GPa})$ & 70.0 & $9.4-22.0$ \\
Elongation at break $(\%)$ & 1.6 & $2.0-2.5$ \\
Cellulose content $(\%)$ & 74.4 & 65.8 \\
Hemicellulose $(\%)$ & 17.9 & 12.0 \\
Lignin $(\%)$ & 3.7 & 9.9 \\
\hline
\end{tabular}

Table 2 Properties of the polymer matrix and hardener.

\begin{tabular}{lcc}
\hline Properties & Green epoxy resin & Hardener \\
\hline Aspect/color & Clear liquid & Clear liquid \\
Density @ 20 ${ }^{\circ} \mathrm{C}\left(\mathrm{g} / \mathrm{cm}^{3}\right)$ & 1.198 & 0.958 \\
Viscosity (mPa.s) @ $20^{\circ} \mathrm{C}$ & 1400 & 60 \\
Refractive Index @ $25^{\circ} \mathrm{C}$ & 1.535 & - \\
Bio based carbon content $(\%)$ & $50-58$ & 0 \\
\hline
\end{tabular}

\subsection{Preparation of hybrid composites}

In order to make the green epoxy matrix, green epoxy (SR Greenpoxy $56^{\circledR}$ ) resin and the hardener (SD Surf Clear ${ }^{\circledR}$ ) were mixed in the ratio of 100:37 by weight. Here the hemp fibre mat of 200 grams per square metre (GSM) and the sisal fibre mat of 210 GSM were used to stack as per the designated layering sequence and was impregnated with green epoxy resin in the mould with dimensions of $20 \mathrm{~cm} \times 20 \mathrm{~cm}$. The mould was then closed and left to cure at $100{ }^{\circ} \mathrm{C}$ for $1 \mathrm{hr}$ in hot press at a constant pressure of 275 bar. After curing, the composites were removed from the mould and post curing was done at $100{ }^{\circ} \mathrm{C}$ for about $10 \mathrm{~min}$. For the purpose of comparison of the results obtained, a pure green epoxy sample, composites with hemp and sisal fibre mats were also prepared. The different layering sequences of the hemp and the sisal fibre mats used for the fabrication of the hybrid composites and the abbreviations for the designated layering sequence are presented in Fig. 2. 


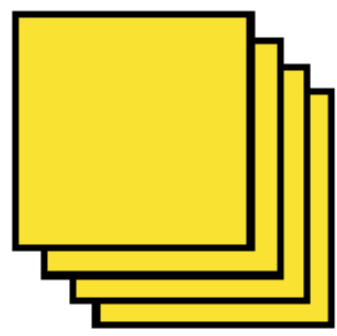

(b)

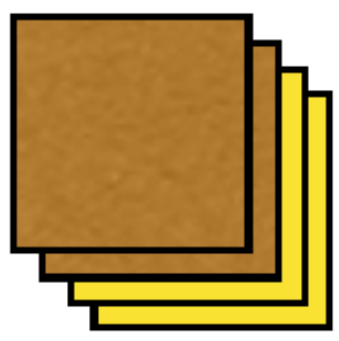

(e)

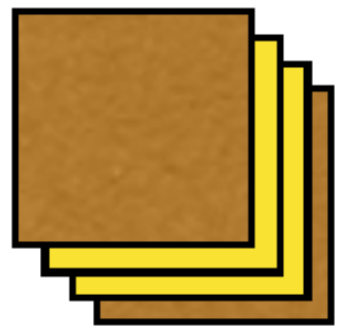

(c)

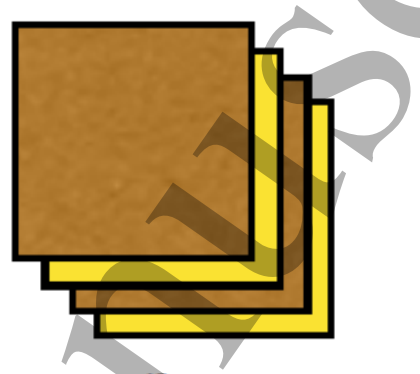

(f)

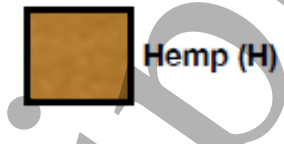

Sisar (S)

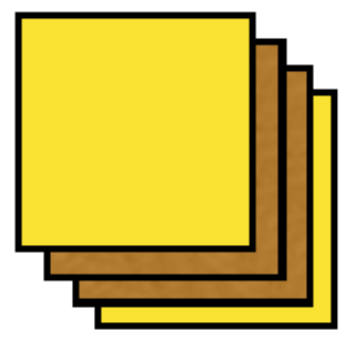

(d) (a)

\section{Fig. 2. Stacking se
3. Characterisation
3.1 Flexural testing}

Fig. 2. Stacking sequences of the green epoxy composites with hemp and sisal fibre mats.

The three-point bending flexural tests were carried out in accordance with ASTM D790 standards. The crosshead speed and gauge length were set to $1.27 \mathrm{~mm} / \mathrm{min}$ and $50 \mathrm{~mm}$, respectively. For each layering sequence, five identical specimens with dimensions of $120 \times 20 x$ $3 \mathrm{~mm}$ were tested and the average values are reported. As an example, the specimen sample before and after the flexural test is presented in Fig. 3.
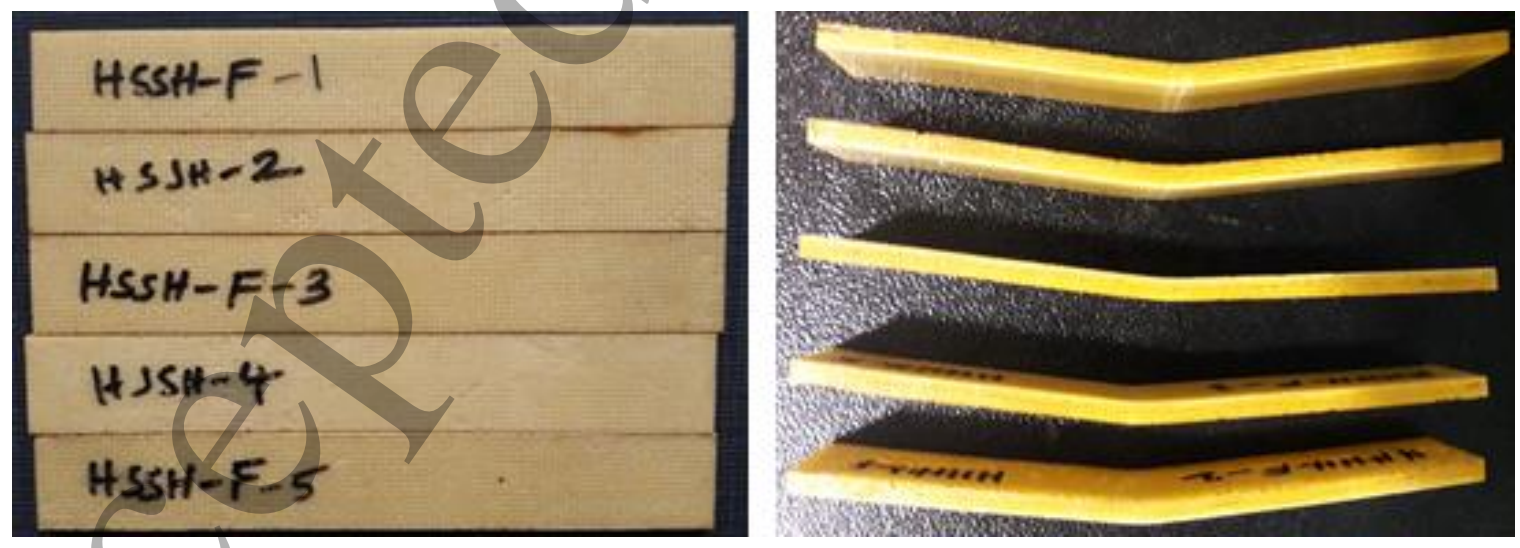

136

Fig. 3. The composite specimens (a) before testing and (b) after the 3-point bending test. 


\subsection{Impact testing}

The Izod impact test was conducted based on ASTM D 256 standards by using Zwick/Roell HIT5.5P impact testing machine. Similar to the flexural testing, for each layering sequence, five identical specimens with dimensions of $63 \times 13 \times 3 \mathrm{~mm}$ were tested and the average results are reported. Figure 4 shows the specimen (samples) before and after the impact testing.

\subsection{Microscopic analysis}

Fig. 4. The pure hemp $(\mathrm{HHHH})$ composite specimens before and after the impact tests.

In order to investigate the failure mechanism of the composites through the fibre-matrix bonding, the SEM analysis was performed for the fractured samples, using a FEI, Quanta 450 scanning electron microscope.

\subsection{Dynamic mechanical analysis}

To study the effect of stacking sequence on the visco-elastic properties of the hybrid composites, the dynamic mechanical analysis was carried out. Hence, a DMA/SDTA861 ${ }^{\mathrm{e}}$ (Mettler Toledo) dynamic mechanical analyser was used. Samples with dimensions of $60 \times 12.5$ $x 3 \mathrm{~mm}$ were used. The storage modulus, loss modulus and the mechanical damping factor were evaluated in a dual cantilever mode within a temperature range of 25 to $150{ }^{\circ} \mathrm{C}$, with a frequency of $1 \mathrm{~Hz}$, at a constant load of $3 \mathrm{~N}$ and a displacement amplitude of $10 \mu \mathrm{m}$. The test was carried out at a heating rate of $3{ }^{\circ} \mathrm{C} / \mathrm{min}$ under nitrogen $\left(\mathrm{N}_{2}\right)$ atmosphere.

\subsection{Thermogravimetric analysis}

The thermal degradation behaviour of the hybrid composites was investigated using a TGA/DSC $3^{+}$thermogravimetric analyser (Mettler Toledo). The thermograms were recorded within a temperature range of $25-600{ }^{\circ} \mathrm{C}$ at a heating rate of $10{ }^{\circ} \mathrm{C} / \mathrm{min}$. All the samples were tested under $\mathrm{N}_{2}$ atmosphere with a flow rate of $60 \mathrm{~mL} / \mathrm{min}$.

\section{Results and discussion}

\subsection{Mechanical properties}

4.1.1 Flexural strength 
The results of the flexural strength and modulus of the pure epoxy, pure hemp, pure sisal and hybrid composite configurations obtained from the 3-point bending test are presented in 169 Figs. 5(a) and 5(b).

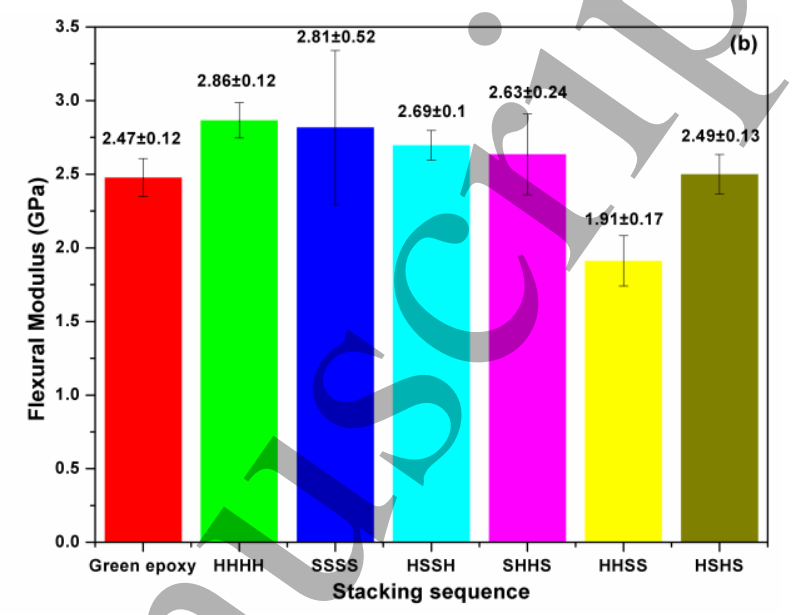

Fig. 5. Effects of stacking sequences of the green epoxy hybridised composites on their (a) flexural strength and (b) flexural modulus.

The maximum flexural strength of $71.94 \mathrm{MPa}$ was obtained for the pure epoxy while the composites with fibre reinforcements were found to have superior flexural modulus than the pure green epoxy. This observation reiterates the fact that flexural strength is governed by the matrix and flexural modulus is a function of the stacking sequence in the laminate. Generally, the flexural strength of any material is based on the combination of compression and tensile behavior at the inner and outer layers, respectively. In this work, the addition of fabrics makes the composite ductile than the pure bio epoxy matrix which was confirmed from the flexible bending of the samples. Since, the bending stiffness of the composites was found decreased due to the poor compatability of the bio resign and fabrics, the failure criteria like fiber breakage and fibre pull out have not been appeared in the outer region of the flexural tested specimens. Such kind of observations were also noticed for flexural strength from different fibre reinforced composite material reported in literature [26] and [7].

In a 3-point bending test performed according to ASTM D790, the specimen is loaded specifically at regions in contact with the support and loading nose. The applied load is immediately carried by the matrix and with the further increase of load; the specimen fails by matrix cracking and breakage. Failure from matrix cracking and breakage is also evident from the images of the failed specimen shown in Fig. 3(b). This behavior in the composite indicates the role of the matrix in carrying the flexural stress. Despite the significant influence from the matrix, the reinforcements also help to carry the load under bending as could be seen from the difference in flexural strength as the fibre stacking sequence was changed.

Among the pure fibre reinforced composites, HHHH composites presented higher flexural strength and modulus than the SSSS composites. The superior performance by HHH under flexural load is due to the higher cellulose content and high fibre aspect ratio of the hemp than the sisal fibre [27-29]. 
For the hybrid composites, the fibre type and stacking sequence in the laminate were also found to influence their flexural properties. Significantly, the use of stronger hemp fibre in the skin (HSSH) resulted in composites with slightly higher strength and modulus than the SHHS arrangement. This is because external layers or skins of the fibre reinforced/composite is subjected to more significant deformation than the fibre layers in the core. Hence, the flexural properties such as strength and stiffness are defined by the external layers [30,31]. Superior strength and modulus for the composites having stronger fibre at the skin and weaker fibre at the core were also reported earlier [6,32]. Both HSHS and HHSS hybrid composite samples 206 behavior of the HSHS and HHSS samples can be attributed to the use of dissimilar fibres with 207 varying fibre properties in the skin and core.

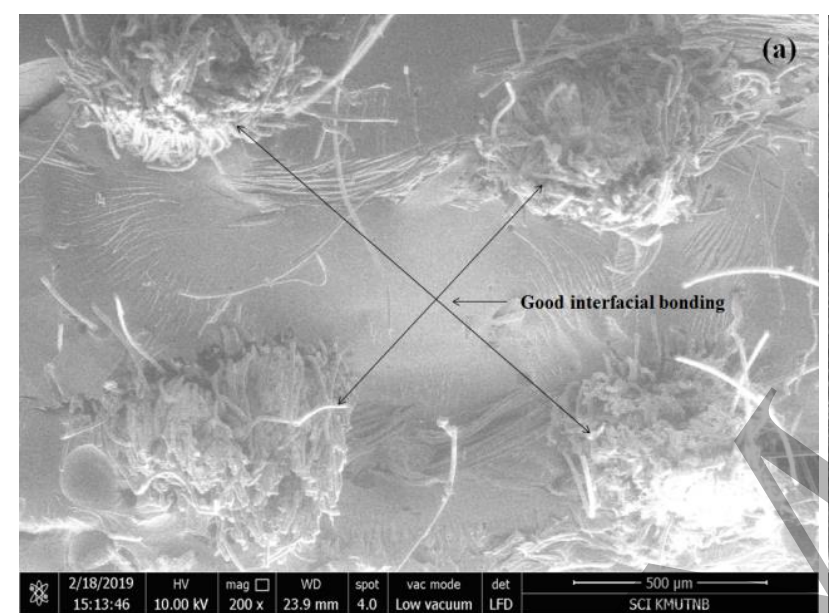

)
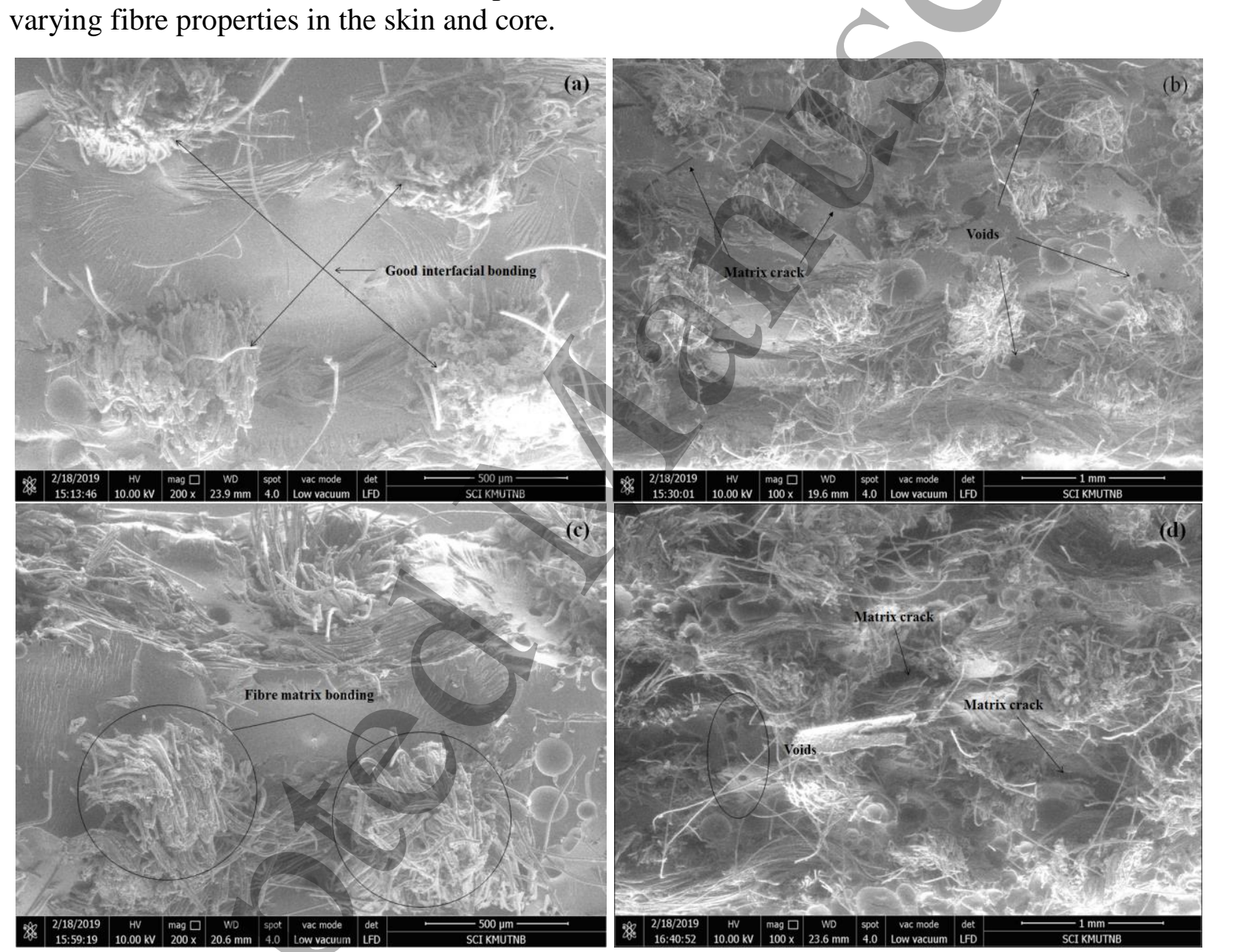

Fig. 6. SEM fractography of flexural tested (a) HHHH, (b) SSSS, (c) HSSH and (d) HHSS composite samples.

217 compatibility between the fibres and resin, as shown in Figs. 6(a) and 6(b). 
The set of data obtained from the one-way analysis of variance (ANOVA) statistical analysis on the mean flexural strength and mean flexural modulus of the various composite configurations at $95 \%$ confidence level are presented in both Tables 3 and 4, respectively.

Table 3 Variance analysis of the flexural strength using one-way ANOVA.

\begin{tabular}{lcccc}
\hline Source & DF & Adj SS & Adj MS & F-Value \\
\hline Between the group & 5 & 1200.8 & 240.16 & P-Value \\
Within the group & 24 & 791.7 & 32.99 & 0.000 \\
\hline DF - Degree of Freedom; Adj SS - Adjacent Sum of Square; Adj MS - Adjacent Mean Square
\end{tabular}

Table 4 Variance analysis of the flexural modulus using one-way ANOVA.

\begin{tabular}{lccccc}
\hline Source & DF & Adj SS & Adj MS & F-Value & P-Value \\
\hline Between the group & 5 & 2957769 & 591554 & 8.56 & 0.000 \\
Within the group & 24 & 1658806 & 69117 & & \\
\hline
\end{tabular}

DF - Degree of Freedom; Adj SS - Adjacent Sum of Square; Adj MS - Adjacent Mean Square

It is evident from both Tables 3 and 4 that $P$-value was less than the significance level, implies that $\alpha \leq 0.05$ for both the flexural strength and modulus. This implies that null hypothesis is not valid and there is a statistically significant difference on the mean flexural strength from one composite stacking sequence to the other.

\subsubsection{Impact strength}

The impact strengths of the green epoxy and its hybrid composites with various stacking sequences are shown in Fig. 7. The green epoxy without reinforcement showed the lowest impact strength compared to the composites reinforced with fibres. This observation indicates the inability of the matrix to absorb the impact energy. It has also been highlighted in the literature that the contribution of the matrix to the energy absorption during impact is negligible [26]. In a fibre reinforced composite material, fibre layer acts as a medium for stress transfer, restrict the formation of cracks in the matrix, and help in withstanding the impact load. Hence, higher impact strength was observed for the pure hemp reinforced composites $(\mathrm{HHHH})$ and the pure sisal reinforced composites (SSSS).

Introducing hemp fibres in hybrid combination with the hemp improves their impact strength. All the hybrid configurations showed superior impact strength than the SSSS. Furthermore, the stacking sequence of the fibre layers was also found to influence the impact strength. Among the hybrid composites, maximum impact strength was exhibited by the HHSS followed by the SHHS and HSHS. Superior impact strength observed for the HHSS could be related to better fibre compatibility between the fibre layers. Since fibres in the outer layer are identical to the adjacent fibre layers in the core; the absorbed impact energy by the outer layer is efficiently transferred to the core.

247 It has been reported and established that fibre-matrix debonding and inter-layer delamination 248 are the principal failure mechanisms responsible for the reduction in the impact strength of a 
249 composite laminate with stacked fibre layers [33]. In this study, the specimens subjected to 250 impact failed by fibre pull-out, as shown in Fig. 8(a) and Fig. 8(b). It is also evident from the 251 fractography images that the specimen did not undergo any delamination post-impact.

252

253

254

255

256

257

258

259

260

261

262

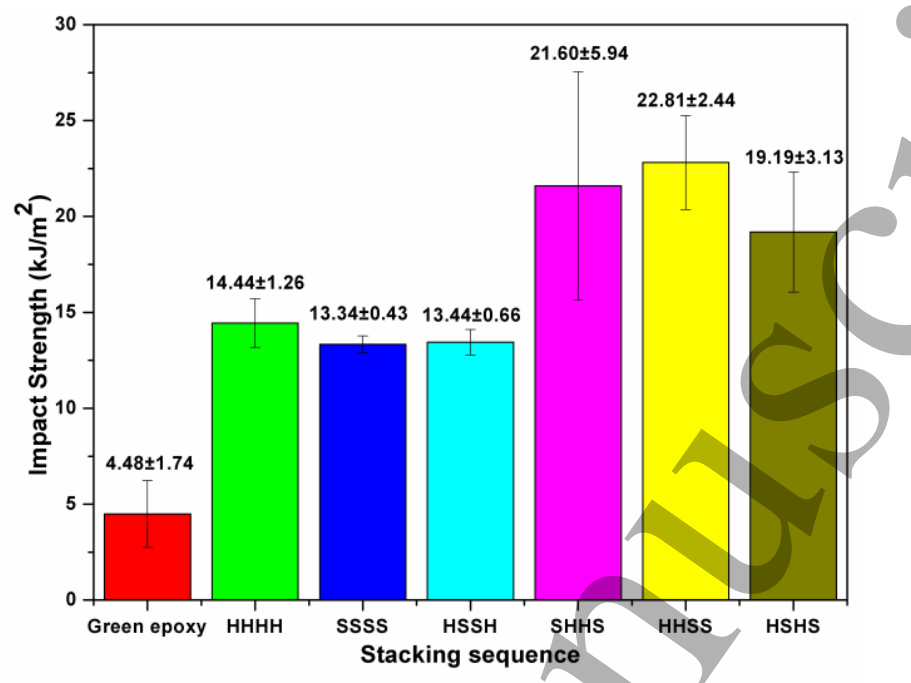

Fig. 7. Effects of stacking sequences of the green epoxy hybridised composites on their impact strengths.

(a)

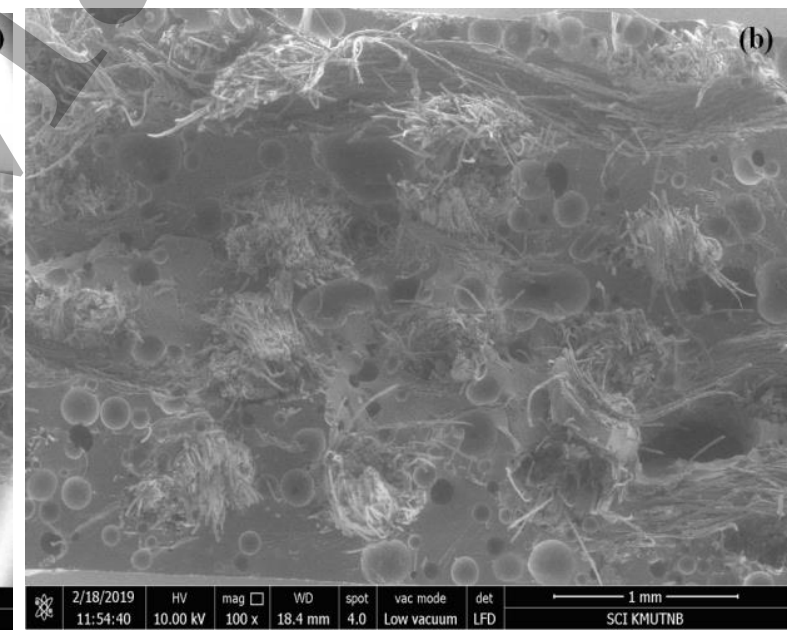

\section{.}

Fig. 8. SEM fractography of impact tested (a) HSSH and (b) HHSS hybrid composite samples.

The variance analysis using one-way ANOVA for mean impact strength of the various composite configurations is presented in Table 5. Similar to the flexural strength and modulus, Pvalue was observed to be less than the significance level of 0.05 . Thus, the null hypothesis can be rejected and there is a statistically significant difference on the mean impact strength between the composite configurations with different stacking sequences.

54
55
56
57
58
59

Table 5 Variance analysis of the impact strength using one-way ANOVA.

\begin{tabular}{llllll}
\hline Source & DF & Adj SS & Adj MS & F-Value & P-Value \\
\hline
\end{tabular}




\section{3}

264

265

266

267

268

269

270

271

272

273

274

275

276

277

278

279

280

281

282

283

284

\subsection{Dynamic mechanical analysis}

Visco-elastic properties and phase changes in the hybrid composites were studied, using dynamic mechanical analysis. The inferences are subsequently discussed.

\subsubsection{Effect of layering sequence on the storage modulus}

Figure 9(a) shows the effect of layering sequence on the storage modulus $\left(E^{\prime}\right)$. In the glassy region, $E$ ' of the investigated composites followed this order: HHHH $>$ SSSS $>$ HHSS > Green epoxy > HSSH > HSHS > SHHS. Since storage modulus represents stiffness of the composites, the maximum storage modulus observed from HHHH sample is credited to the superior tensile properties of the hemp over the sisal. The E' of neat green epoxy was higher compared to SHHS, HSHS and HSSH hybrid composite samples until $55^{\circ} \mathrm{C}$. Beyond $55^{\circ} \mathrm{C}$, the storage modulus of neat green epoxy dropped suddenly and reached zero. It was corroborated that epoxy loses its stiffness owing to the increased molecular movements at higher temperature [12]. Pure and hybrid composites showed comparatively higher storage modulus in the transition region of 60 ${ }^{\circ} \mathrm{C}-100{ }^{\circ} \mathrm{C}$ than the green epoxy. Improvement in storage modulus due to the fibre incorporation into the matrix in the transition region was in accordance with the findings from the previous studies [34-36].

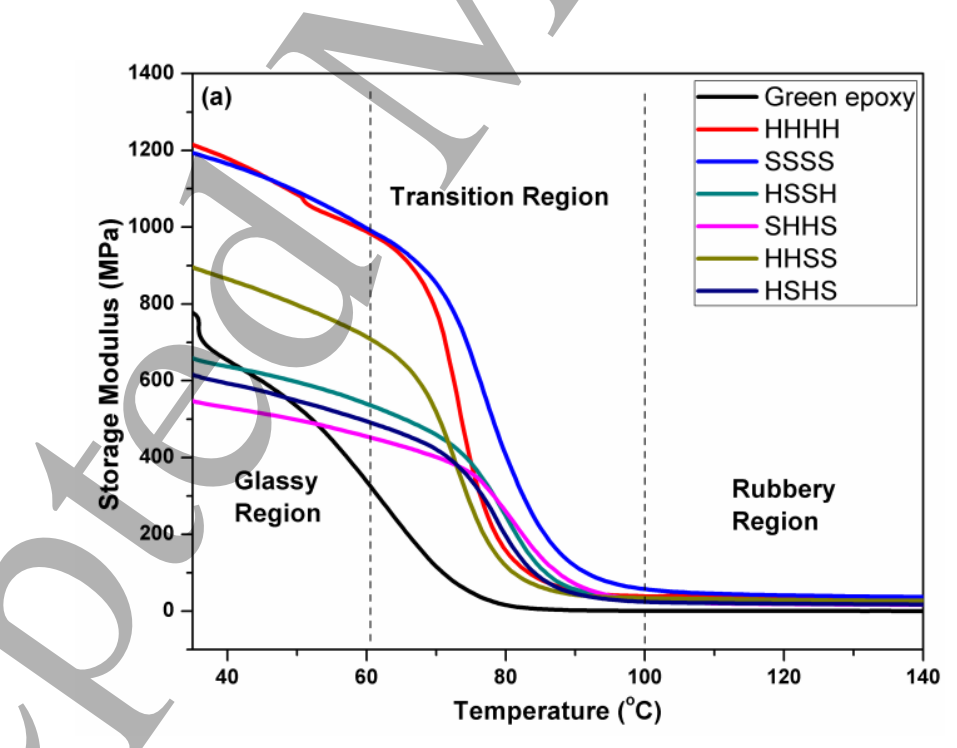

Fig. 9(a). Variation in storage modulus of the green epoxy hybridised composites

Additionally, the effects of reinforcement on storage modulus of the composites were further characterised by a coefficient, C [37], using Equ. (1).

$$
\mathrm{C}=\frac{E_{G}^{I} / E_{R}^{I} \text { composite }}{E_{G}^{I} / E_{R}^{I} \text { resin }}
$$


where $E_{G}^{\prime}$ and $E_{R}^{\prime}$ are the storage modulus values of composites in the glassy and rubbery regions, respectively. The higher value of $\mathrm{C}$ indicates lower efficiency of fibre reinforcement and vice-versa. The coefficients of the composites were calculated and their results are tabulated in Table 6.

Table 6 Co-efficient of the effectiveness of composites.

\begin{tabular}{cc}
\hline Composites & Co-efficient of effectiveness (C) \\
\hline HHHH & 0.01570 \\
SSSS & 0.88144
\end{tabular}

\begin{abstract}
291 Based on the analysis, varying the stacking sequence and introducing fibres in hybrid 292 combination was less effective in terms of thermal properties.

\section{$293 \quad$ 4.2.2 Effect of layering sequence on loss módulus}

294 Loss modulus $\left(E^{\prime \prime}\right)$ defines the amount of energy dissipated by the composites under cyclic 295 loading. Figure 9(b) illustrates the variation of loss modulus of green epoxy, pure and hybrid 296 composites at various temperatures. The glass transition temperature, $\mathrm{T}_{\mathrm{g}}$ shifted from $61.9^{\circ} \mathrm{C}$ for 297 green epoxy to a temperature range of $70^{\circ} \mathrm{C}-80^{\circ} \mathrm{C}$ as the reinforcements were introduced into 298 the matrix. Further observation on the peak loss modulus was that both pure HHHH and SSSS 299 composite samples displayed considerably larger values than the hybrid counterparts. Similar 300 observations were also reported in a study on the hybrid bamboo-kenaf fibres reinforced 301 composites [38]. The highest loss modulus was observed by the pure kenaf/epoxy composites 302 followed by bamboo/epoxy composites. Hybrid configurations such as HSSH, SHHS and HSHS 303 composite samples exhibited lower peak modulus than the other configurations. In all these 304 configurations, the adjacent layers within the laminate are dissimilar fibre layers. Due to their 305 varying fibre properties, the energy dissipation behaviour was affected, consequently, it had an 306 impact on the peak loss modulus, as shown in Table 7.
\end{abstract}


307

308

309

310

311

312

313

314

315

316

317

318

319

320

321

322

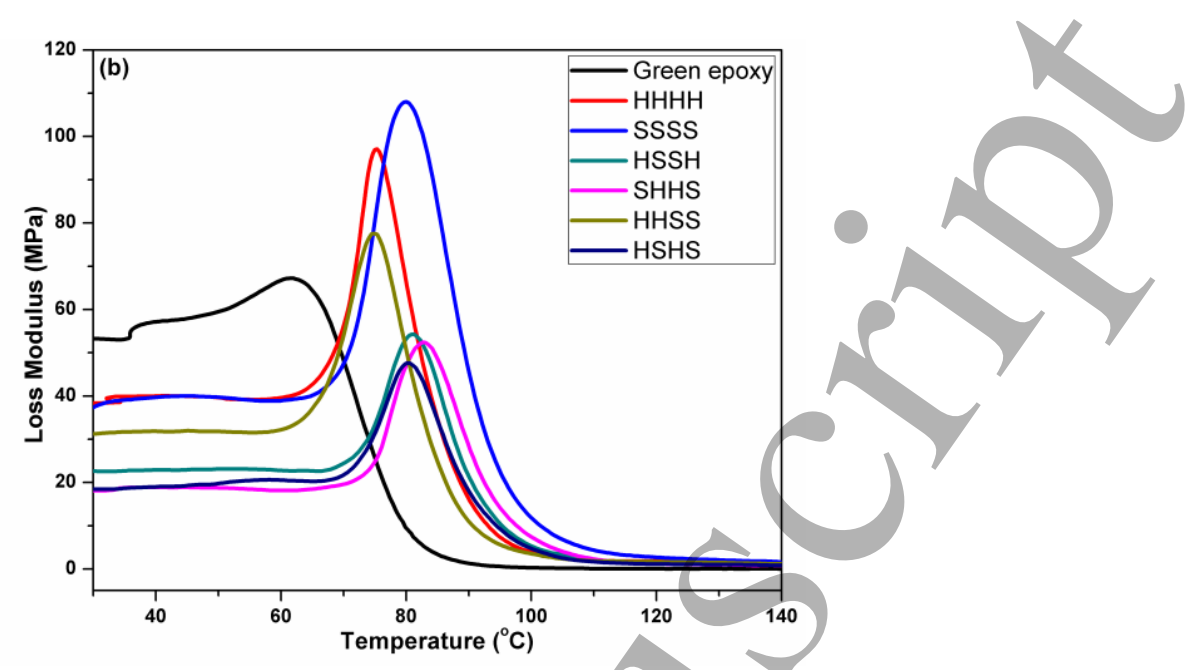

Fig. 9(b). Variation in loss modulus of the green epoxy hybridised composites

Table 7 Glass transition temperatures of pure and hybrid composites obtained from loss modulus and tan delta plots.

\begin{tabular}{ccccc}
\hline \multirow{2}{*}{ Samples } & $\begin{array}{c}\text { Peak height of loss } \\
\text { modulus curve } \\
(\mathrm{MPa})\end{array}$ & $\begin{array}{c}\text { Peak } \\
\text { height of } \\
\text { Tan delta }\end{array}$ & $\begin{array}{c}\text { Temperature }\left({ }^{\circ} \mathrm{C}\right) \\
\mathrm{T}_{\mathrm{g}} \text { from Tan } \\
\text { delta }\end{array}$ & $\mathrm{T}_{\mathrm{g}}$ from E" \\
\hline Green epoxy & 67.2454 & 0.79425 & 83.635 & 61.9116 \\
HHHH & 97.1006 & 0.48675 & 82.253 & 75.3581 \\
SSSS & 108.0700 & 0.44599 & 87.589 & 80.0455 \\
HSSH & 54.2625 & 0.43715 & 87.356 & 80.8571 \\
SHHS & 52.4075 & 0.43800 & 89.379 & 82.7050 \\
HHSS & 77.6106 & 0.48432 & 81.263 & 74.8622 \\
HSHS & 47.6246 & 0.45260 & 87.657 & 80.1912 \\
\hline
\end{tabular}

\subsubsection{Effect of layering sequence on tan delta}

The tan delta values which represent the damping characteristic of neat green epoxy, single fibre and hybrid fibre composites with the temperature are shown in Fig. 9(c). The ratio of loss modulus (viscous properties) to storage modulus (elastic properties) is referred to as the damping factor. A higher degree of molecular movement in the polymeric chains is a desirable phenomenon to have greater damping characteristic [39]. Introducing fibre reinforcements restricts the molecular movements within the polymeric chains, unlike pure epoxy which has the highest molecular movement. As a consequence, the composites with fibre reinforcements possess lower peak tan delta values than the green epoxy (Table 7). It was attributed to the enhanced fibre-matrix bonding in the composites. Moreover, the reduction of tan delta values of both the pure and hybrid composites suggested that improvement of rigidity at the interface can 
reduce the molecular movement at the interfacial zone. It resulted in better damping. Besides, the effectiveness of fibre reinforcement was also indicated by the least value of tan delta.

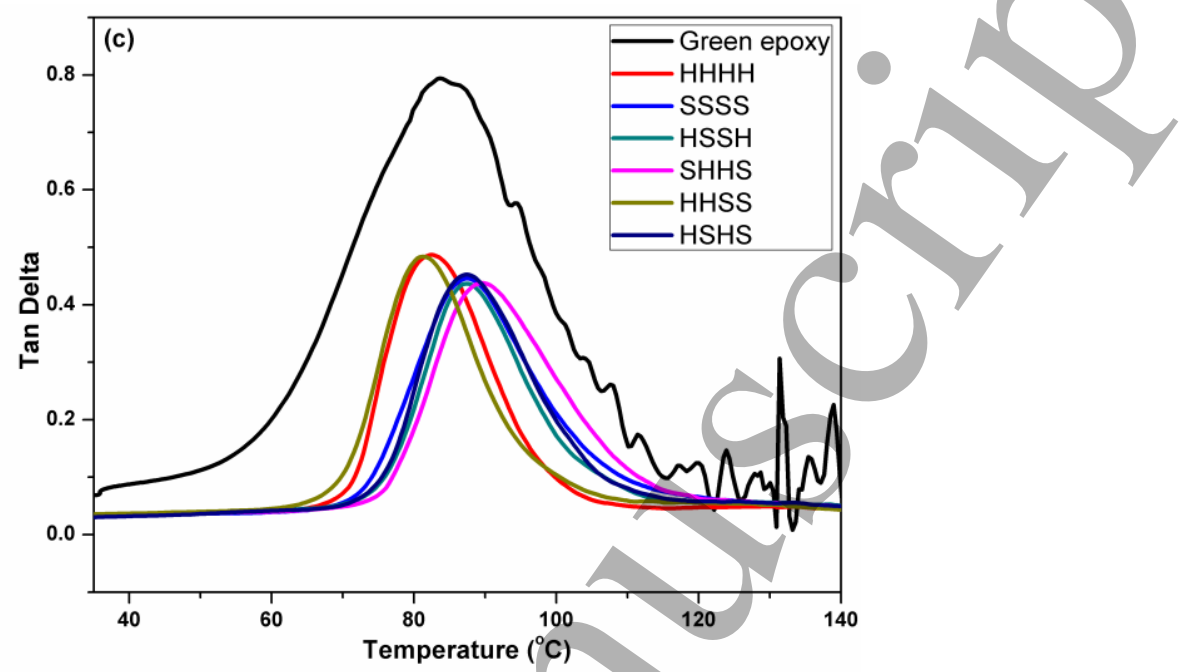

Fig. 9(c). Variation in tan delta of the green epoxy hybridised composites

Pure hemp (HHHH) and pure sisal (SSSS) fibre reinforced composites possessed a damping factor of 0.48675 and 0.44599 , respectively. This implies that damping factor for the hybrid composites were dictated by the fibre properties and fibre stacking sequence similar to the observations in loss modulus and storage modulus. The varying stiffness and fibre aspect ratio due to the fibre arrangements in HHSS and HSHS composites helped them to retain higher tan delta than the SHHS, HSSH and SSSS configurations. The Tg obtained from the peak tan delta values from the hybrid composites also showed only a slight shift in temperature compared to the green epoxy.

\subsubsection{Effect of layering sequence on Cole-Cole plots or Wicket plots}

Structural aspects such as homogeneity or heterogeneity of a polymeric material can be analysed from Cole-Cole or wicket plots [37,40]. A smooth and semi-circular plot indicates homogeneity, while imperfect or elliptical plot represents the heterogeneity [41]. Pure sisal (SSSS) and hemp (HHHH) fibre composites displayed a broader peak compared to the hybrid composites which shows a degree of homogeneity, as shown in Fig. 9(d). Introducing hemp and sisal in hybrid combination induced heterogeneity, as reflected from the narrow peaks. According to some earlier reports, the imperfect shape refers to better interfacial adhesion within the fibres and matrix in a polymeric composite [42,43]. 


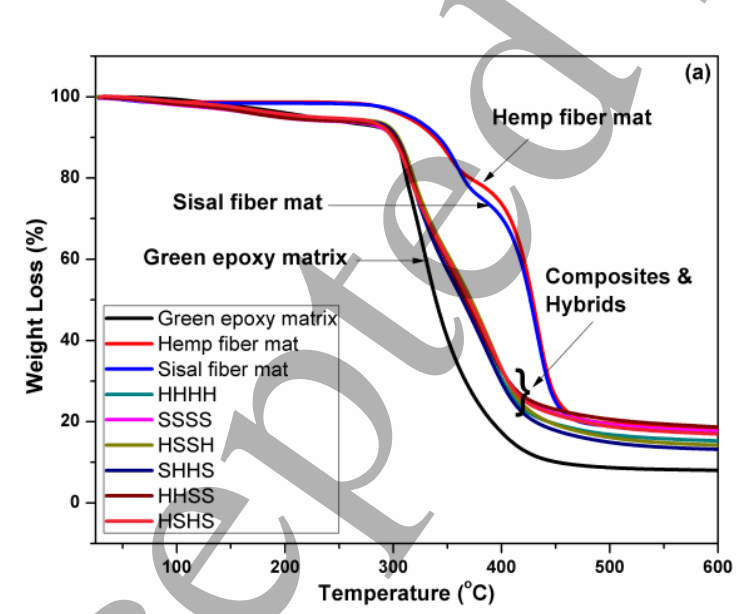

\subsection{Thermogravimetric analysis}

Fig. 9(c). Cole-Cole plot of the green epoxy hybridised composites

To examine the thermal stability of the hybrid composites, the thermogravimetric analysis was performed. The primary and derivative thermograms of pure green epoxy matrix, pure hemp and sisal fibre mats and the hybrid composites are shown in Figs. 10(a) and 10(b). The decomposition of pure green epoxy matrix took place in a single stage. It can be observed that there is no peak found in the temperature range of $30-100{ }^{\circ} \mathrm{C}$ indicating the absence of moisture content. The inflection point corresponding to the maximum degradation was found at $328.62{ }^{\circ} \mathrm{C}$ for the pure green epoxy matrix. This may be attributed to the degradation of main polymeric chains of green epoxy matrix. The weight loss in the fibres occurred mainly due to the decomposition of cellulose, hemicellulose and lignin components present in them. The higher the decomposition temperature recorded denotes a greater the thermal stability [44].

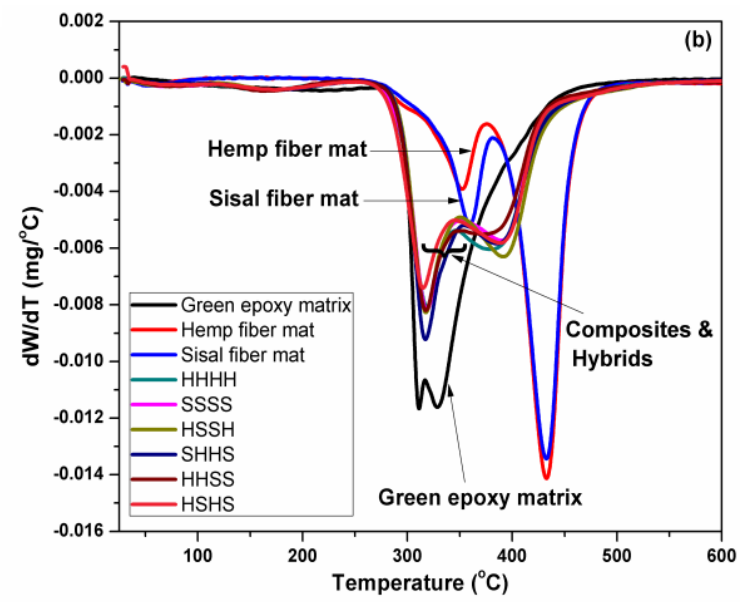

Fig. 10. (a) Primary thermograms and (b) derivative thermograms of the green epoxy hybridised composites.

From the Fig 10, it can be established that the degradation process of the fibres took place 358 in different stages. The evaporation of the moisture content in the fibres took place between 30$359100{ }^{\circ} \mathrm{C}$. It can also be observed that the degradation of the main components occurred in two 
stages. The degradation in the temperature range of $320-360{ }^{\circ} \mathrm{C}$ may be attributed to the decomposition of the least stable hemicellulose in the sisal and hemp fibres. Furthermore, the decomposition of cellulose and lignin contents in the fibres occurred at a temperature range of $410-450{ }^{\circ} \mathrm{C}$. The higher decomposition temperature of cellulose components in the fibres may be due to strong crystalline structure of cellulose, which is resistant to hydrolysis [45]. From the thermograms obtained, it was evident that both pure hemp and the sisal fibre mats possessed a very similar range of thermal stability, but they are greater than that of the pure green epoxy matrix, as depicted in Fig. 10(b). In addition, the thermal stability of the composites with hemp/green epoxy (HHHH) and sisal/green epoxy (SSSS) was also investigated. It has been reported that the thermal stability of the composites is governed by both the matrix material and the individual reinforcement material [46]. From the thermograms (Fig. 10), it was observed that the main degradation of the composites occurred in two steps. Also, it was also evident that the incorporation of sisal and hemp fibre mats greatly enhanced the thermal stability of the composites, when compared with the pure green epoxy matrix. This could be attributed to the high cellulose content in the sisal and hemp fibres. The sisal/green epoxy composites exhibited higher thermal stability of $391.06{ }^{\circ} \mathrm{C}$ compared to the hemp/green epoxy composites of 379.54 ${ }^{\circ} \mathrm{C}$. The thermal stability of the hybrid composites slightly increased compared with the HHHH and SSSS composites. In case of the hybrid composites, the HSSH sample exhibited the highest thermal stability of $392.5{ }^{\circ} \mathrm{C}$, followed by the HSHS sample with a thermal stability of 388.56 ${ }^{\circ} \mathrm{C}$. It was observed that the values of thermal stability of the hybrid composites, with exception of HHSS samples, were higher than that of the pure green epoxy matrix, HHHH and SSSS composite samples. This observation may be attributed to the improved fibre matrix interaction. 383 material, fibres, the pure composite systems and the hybrid composites are presented in Table 8.

Table 8 Inflection temperatures corresponding to the maximum degradation rate. Degradation temperature $\left({ }^{\circ} \mathrm{C}\right)$

\begin{tabular}{|c|c|c|c|c|c|c|c|}
\hline \multirow{3}{*}{ Samples } & \multicolumn{6}{|c|}{ Degradation temperature $\left({ }^{\circ} \mathrm{C}\right)$} & \multirow{3}{*}{$\begin{array}{c}\text { Residue } \\
(\%)\end{array}$} \\
\hline & \multicolumn{3}{|c|}{ Step 1} & \multicolumn{3}{|c|}{ Step 2} & \\
\hline & Onset & Inflection & End set & Onset & Inflection & End set & \\
\hline Green epoxy & 302.19 & 311.36 & 368.24 & - & - & - & 7.46 \\
\hline Hemp fibre mat & 322.77 & 352.81 & 361.77 & 412.48 & 431.98 & 448.37 & 16.11 \\
\hline Sisal fibre mat & 330.62 & 358.76 & 369.36 & 413.50 & 432.84 & 448.76 & 16.08 \\
\hline НHНH & 300.26 & 318.00 & 328.44 & 361.49 & 379.54 & 413.33 & 15.50 \\
\hline SSSS & 301.69 & 318.47 & 329.29 & 373.44 & 391.06 & 412.13 & 18.01 \\
\hline HSSH & 0000 & 317.82 & 328.98 & 372.12 & 392.5 & 414.64 & 14.44 \\
\hline SHHS & & 316.72 & 330.64 & 369.54 & 385.57 & 412.96 & 13.33 \\
\hline HHSS & 300.52 & 317.62 & 328.40 & 366.6 & 372.88 & 410.23 & 18.86 \\
\hline HSHS & 296.69 & 314.77 & 325.43 & 366.85 & 388.56 & 414.16 & 17.26 \\
\hline
\end{tabular}

386

The mechanical, dynamic mechanical and thermogravimetric analysis of the sisal (S) and hemp $(\mathrm{H})$ reinforced green epoxy hybrid composites were studied, with various fibre stacking sequences within the laminates. The presence of hemp fibre in the skin and sisal at core (HSSH) 391 resulted/in composite with the best flexural strength and flexural modulus among the hybrid 
composites. Hybrid composites with both sisal and hemp in the skin and core (HHSS) exhibited maximum impact strength of $22.81 \mathrm{~kJ} / \mathrm{m}^{2}$ compared to the neat green epoxy, pure sisal, pure hemp and hybrid fibres reinforced polymer composites (among all samples). The superior impact properties for the hybrid (HHSS) composites were due to the absence of delamination as evident from the micrographs, which showed only fibre pull-out. The maximum mechanical performance depicts the benefits of hybridisation technique and desired fibre stacking sequence in composite materials. However, pure hemp (HHHH) fibre reinforced composite recorded the highest flexural strength and modulus of $60.56 \mathrm{MPa}$ and $2.86 \mathrm{GPa}$, respectively, when compared with other fibre reinforced polymer composite samples. This implies that hybridisation of hemp fibre with sisal fibre in studied stacking sequences or configurations reduced both flexural strength and modulus of hemp fibre. It was further evident as the composite sample of pure sisal (SSSS) fibre recorded lower flexural strength and modulus when compared with the composite sample of pure hemp (HHHH) fibre.

Conclusively, the hybrid composites with dissimilar fibres in their adjacent layers, namely: HHSS and HSHS exhibited inferior flexural properties. Though, they outperformed the other hybrid configurations in terms of impact strength and thermal stability, as reflected from the highest peak modulus obtained from the dynamic mechanical analysis and higher char residue from the thermogravimetric analysis, respectively. Evidently, variation in their properties from one stacking sequence to the other indicates that hybrid composites can be tailored to meet out the suitable applications.

412

413

414

415

416

417

418

419

420

421

422

423

424

425

426

427

428

429

430

431 432

\section{Conflict of interest}

None.

\section{Acknowledgement}

This research was completely supported by the King Mongkut's University of Technology North Bangkok (KMUTNB), Thailand through the Post-Doctoral Program (Grant No. KMUTNB 61-Post-01 and KMUTNB-63-KNOW-001) and (Grant No. KMUTNB-61-Post03 and KMUTNB-63-KNOW-001). Therefore, all the authors hereby express their sincere appreciations to the KMUTNB.

\section{References}

[1] M. Ramesh, K. Palanikumar, K.H. Reddy, Plant fibre based bio-composites: Sustainable and renewable green/materials, Renew. Sustain. Energy Rev. 79 (2017) 558-584. doi:10.1016/j.rser.2017.05.094.

[2] K. Senthilkumar, N. Saba, M. Chandrasekar, M. Jawaid, N. Rajini, O.Y. Alothman, S. Siengchin, Evaluation of mechanical and free vibration properties of the pineapple leaf fibre reinforced polyester composites, Constr. Build. Mater. (2019). doi:10.1016/j.conbuildmat.2018.11.081.

[3] and N.R. Kumar, K. Senthil, I. Siva, P. Jeyaraj, JT Winowlin Jappes, S. C. Amico, Synergy of fiber length and content on free vibration and damping behavior of natural 
433 fiber reinforced polyester composite beams, Mater. Des. 56 (2014) 379-386.

434 [4] M. Chandrasekar, M.R. Ishak, S.M. Sapuan, Z. Leman, M. Jawaid, A review on the

435

436

437

438

439

440

441

442

443

444

445

446

447

448

449

450

451

452

453

454

455

456

457

458

459

460

461

462

463

464

465

466

467

468

469

470 characterisation of natural fibres and their composites after alkali treatment and water absorption, Plast. Rubber Compos. (2017). doi:10.1080/14658011.2017.1298550.

[5] R.M. Shahroze, M.R. Ishak, M.S. Salit, Z. Leman, M. Asim, M. Chandrasekar, Effect of organo-modified nanoclay on the mechanical properties of sugar palm fiber-reinforced polyester composites, BioResources. 13 (2018) 7430-7444.

[6] M. Jawaid, H.P.S.A. Khalil, A.A. Bakar, Woven hybrid composites : Tensile and flexural properties of oil palm-woven jute fibres based epoxy composites, Mater. Sci. Eng. A. 528 (2011) 5190-5195. doi:10.1016/j.msea.2011.03.047.

[7] K. Senthilkumar, N. Saba, N. Rajini, M. Chandrasekar, M. Jawaid, S. Siengchin, O.Y. Alotman, Mechanical properties evaluation of sisal fibre reinforced polymer composites: A review, Constr. Build. Mater. (2018). doi:10.1016/j.conbuildmat.2018.04.143.

[8] K. John, S.V. Naidu, Tensile properties of unsaturated polyester-based sisal fiber - Glass fiber hybrid composites, J. Reinf. Plast. Compos. 23 (2004) 1815-1819. doi: $10.1177 / 0731684404041147$.

[9] P. Noorunnisa Khanam, M. Mohan Reddy, K. Raghu, K. John, S. Venkata Naidu, Tensile, Flexural and Compressive Properties of Sisal/Silk Hybrid Composites, J. Reinf. Plast. Compos. 26 (2007) 1065-1070. doi:10.1177/0731684407079347.

[10] M. Boopalan, M. Niranjanaa, M.J. Umapathy, Study on the mechanical properties and thermal properties of jute and banana fiber reinforced epoxy hybrid composites, Compos. Part B Eng. 51 (2013) 54-57. doi:10.1016/j.compositesb.2013.02.033.

[11] S.K. Nayak, S. Mohanty, S.K. Samal, Influence of short bamboo/glass fiber on the thermal, dynamic mechanical and rheological properties of polypropylene hybrid composites, Mater. Sci. Eng. A. 523 (2009) 32-38. doi:10.1016/j.msea.2009.06.020.

[12] D. Shanmugam, M. Thiruchitrambalam, Static and dynamic mechanical properties of alkali treated unidirectional continuous Palmyra Palm Leaf Stalk Fiber/jute fiber reinforced hybrid polyester composites, Mater. Des. 50 (2013) 533-542. doi:10.1016/j.matdes.2013.03.048.

[13] V.S. Srinivasan, S. Rajendra Boopathy, D. Sangeetha, B. Vijaya Ramnath, Evaluation of mechanical and thermal properties of banana-flax based natural fibre composite, Mater. Des. 60 (2014) 620-627. doi:10.1016/j.matdes.2014.03.014.

[14] S. Panthapulakkal, M. Sain, Injection- molded short hemp fiber/glass fiber- reinforced polypropylene hybrid composites-Mechanical, water absorption and thermal properties, J. Appl. Polym. Sci. 103 (2007) 2432-2441.

[15] S.K. Saw, C. Datta, Thermomechanical properties of jute/bagasse hybrid fibre reinforced epoxy thermoset composites, BioResources. 4 (2009) 1455-1476. doi:10.15376/BIORES.4.4.1455-1475. 
[16] K.L. Pickering, M.G.A. Efendy, T.M. Le, A review of recent developments in natural fibre composites and their mechanical performance, Compos. Part A Appl. Sci. Manuf. 83 (2016) 98-112. doi:10.1016/j.compositesa.2015.08.038.

[20] F. Miculescu, A. Maidaniuc, S.I. Voicu, V.K. Thakur, G.E. Stan, L.T. Ciocan, Progress in hydroxyapatite-starch based sustainable biomaterials for biomedical bone substitution applications, ACS Sustain. Chem. Eng. 5 (2017) 8491-8512.

485

486

487

488

489

490

491

492

493

494

495

496

497

498

499

500

501

502

503

[21] I. Gan, W.S. Chow, Antimicrobial poly (lactic acid)/cellulose bionanocomposite for food packaging application: A review, Food Packag. Shelf Life. 17 (2018) 150-161.

[22] D.M. Panaitescu, A.N. Frone, I. Chiulan, Nanostructured biocomposites from aliphatic polyesters and bacterial cellulose, Ind. Crops Prod. 93 (2016) 251-266.

[23] B.J. Saradava, A.J. Kathwadia, A.D. Gorviyala, V.K. Joshi, Mechanical Characterization of Hemp Fiber Reinforced Polyester Composites: A Review, J. Polym. Compos. 4 (2019) $1-3$.

[24] A. Pappu, K.L. Pickering, V.K. Thakur, Manufacturing and characterization of sustainable hybrid composites using sisal and hemp fibres as reinforcement of poly (lactic acid) via injection moulding, Ind. Crops Prod. 137 (2019) 260-269.

[25] M. Jawaid, H.P.S. Abdul Khalil, Cellulosic/synthetic fibre reinforced polymer hybrid composites: A review, Carbohydr. Polym. 86 (2011) 1-18. doi:10.1016/j.carbpol.2011.04.043.

[26] P.K. Mallick, Fiber-reinforced composites: materials, manufacturing, and design, CRC press, 2007.

[27] A. Shahzad, Hemp fiber and its composites - A review, J. Compos. Mater. 46 (2012) 973986. doi:10.1177/0021998311413623.

[28] A. Zegaoui, H. Zhang, M. Derradji, A.Q. Dayo, W. Cai, L. Zhang, J. Wang, A. Medjahed, H.A. Ghouti, Impact of sodium bicarbonate treatment of waste hemp fibers on the properties of dicyanate ester of bisphenol-A/bisphenol-A-based benzoxazine resin composites, Proc. Inst. Mech. Eng. Part L J. Mater. Des. Appl. 0 (2019) 1-14. doi:DOI: $10.1177 / 1464420719830431$.

507

508 [29] K. Joseph, B. James, S. Thomas, L.H. De Carvalho, A review in sisal fiber reinforced 

polymer, Re. 3 (1999) 367-379. doi:10.1590/1807-1929/agriambi.v3n3p367-379.

[30] K.S. Ahmed, S. Vijayarangan, C. Rajput, Mechanical behavior of isothalic polyesterbased untreated woven jute and glass fabric hybrid composites, J. Reinf. Plast. Compos. 25 (2006) 1549-1569. doi:10.1177/0731684406066747.

[31] T. Munikenche Gowda, a. C.B. Naidu, R. Chhaya, Some mechanical properties of untreated jute fabric-reinforced polyester composites, Compos. Part A Appl. Sci. Manuf. 30 (1999) 277-284. doi:10.1016/S1359-835X(98)00157-2.

[32] K. Senthil Kumar, I. Siva, N. Rajini, J.T. Winowlin Jappes, S.C. Amico, Layering pattern effects on vibrational behavior of coconut sheath/banana fiber hybrid composites, Mater. Des. 90 (2016) 795-803. doi:10.1016/j.matdes.2015.11.051.

[33] M. Idicula, N.R. Neelakantan, Z. Oommen, K. Joseph, S. Thomas, A study of the mechanical properties of randomly oriented short banana and sisal hybrid fiber reinforced polyester composites, J. Appl. Polym. Sci. 96 (2005) 1699-1709. doi:10.1002/app.21636.

[34] K. Jayanarayanan, S. Thomas, K. Joseph, Dynamic mechanical analysis of in situ microfibrillar composites based on PP and PET, Polym. Plast. Technol. Eng. 48 (2009) $455-463$.

[35] P.A. Sreekumar, R. Saiah, J.M. Saiter, N. Leblanc, K. Joseph, G. Unnikrishnan, S. Thomas, Effect of chemical treatment on dynamic mechanical properties of sisal fiberreinforced polyester composites fabricated by resin transfer molding, Compos. Interfaces. 15 (2008) 263-279.

[36] W. He, T. Xing, G.X. Liao, W. Lin, F. Deng, X.G. Jian, Dynamic mechanical properties of PPESK/silica hybrid materials, Polym. Plast. Technol. Eng. 48 (2009) 164-169.

[37] O. Senturk, A.E. Senturk, M. Palabiyik, Evaluation of hybrid effect on the thermomechanical and mechanical properties of calcite/SGF/PP hybrid composites, Compos. Part B Eng. 140 (2018) 68-77. doi:10.1016/j.compositesb.2017.12.021.

[38] S.S. Chee, M. Jawaid, M.T.H. Sultan, O.Y. Alothman, L.C. Abdullah, Thermomechanical and dynamic mechanical properties of bamboo/woven kenaf mat reinforced epoxy hybrid composites, Compos. Part B Eng. $163 \quad$ (2019) 165-174. doi:10.1016/j.compositesb.2018.11.039.

[39] M. Jacob, B. Francis, K.T. Varughese, S. Thomas, The effect of silane coupling agents on the viscoelastic properties of rubber biocomposites, Macromol. Mater. Eng. 291 (2006) 1119-1126. doi:10.1002/mame.200600171.

[40] Y. Karaduman, M.M.A. Sayeed, L. Onal, A. Rawal, Viscoelastic properties of surface modified jute fiber/polypropylene nonwoven composites, Compos. Part B Eng. 67 (2014) 111-118. doi:10.1016/j.compositesb.2014.06.019.

[41] P. Joseph, G. Mathew, K. Joseph, G. Groeninckx, S. Thomas, the Journal of Chemical Physics 125, 214701 2006_, Compos. Part A Appl. Sci. Manuf. 34 (2003) 275-290. doi:10.1016/S1359-835X(02)00020-9. 
547 [42] V. Panwar, K. Pal, An optimal reduction technique for rGO/ABS composites having high548 549

550 551 552 553 554 555 end dynamic properties based on Cole-Cole plot, degree of entanglement and C-factor, Compos. Part B Eng. 114 (2017) 46-57. doi:10.1016/j.compositesb.2017.01.066.

[43] N. Saba, Paridah, K. Abdan, N.A. Ibrahim, Dynamic mechanical properties of oil palm nano filler/kenaf/epoxy hybrid nanocomposites, Constr. Build. Mater. 124 (2016) 133138. doi:10.1016/j.conbuildmat.2016.07.059.

[44] S. Oza, H. Ning, I. Ferguson, N. Lu, Effect of surface treatment on thermal stability of the hemp-PLA composites: Correlation of activation energy with thermal degradation, Compos. Part B Eng. 67 (2014) 227-232. doi:10.1016/j.compositesb.2014.06.033.

[45] M.M. Kabir, H. Wang, K.T. Lau, F. Cardona, Effects of chemical treatments on hemp fibre structure, Appl. Surf. Sci. 276 (2013) 13-23. doi:10.1016/j.apsusc.2013.02.086.

[46] M. Jawaid, H.P.S. Abdul Khalil, O.S. Alattas, Woven hybrid biocomposites: Dynamic mechanical and thermal properties, Compos. Part A Appl. Sci. Manuf. 43 (2012) 288-293. 560

561 doi:10.1016/j.compositesa.2011.11.001. 